\title{
Knemometry and the assessment of growth in premature babies
}

\author{
Alan T Gibson, Richard G Pearse, Jeremy K H Wales
}

\begin{abstract}
The characteristics of a knemometer designed for accurate lower leg measurement in babies were assessed. Repeated measurement of a $100 \mathrm{~mm}$ Perspex rod gave a mean length of $99.993 \mathrm{~mm}$ and a mean SD of $0 \cdot 058$. When used to measure leg length, technical error of the measurement technique was 0.31 with a mean leg length of $98.49 \mathrm{~mm}$ (coefficient of variation $0 \cdot 31 \%$ ).
\end{abstract}

Leg lengths measured at birth in 324 babies from 23 to 42 weeks' gestation gave an estimated in utero leg length velocity of $0.43 \mathrm{~mm} /$ day $(95 \%$ confidence interval 0.41 to 0.45 ). Assessment of interobserver variation showed poor agreement in absolute values of leg length, although similar estimates of leg length velocity could be obtained.

The neonatal knemometer allows measurements to be made in situations where conventional growth measurements are not possible. It is believed that knemometry has an important role in accurate evaluation of factors that can influence short term bone growth. (Arch Dis Child 1993; 69: 498-504)

The ability to accurately measure growth is extremely important in babies, firstly because of the very rapid growth rate seen in the postnatal period and secondly because of the way that many differing factors may have a common effect in disturbance of normal growth. This is particularly true in the small, sick, and premature infant, yet it is in precisely these babies that such measurements are most difficult to make. Assessment of growth is most commonly made by sequential weight measurements, yet even this may not be possible in a sick ventilated baby. In addition, weight may be influenced by changes in fat and fluid deposition that are not necessarily reflected by changes in linear growth. ${ }^{12}$ Measurement of length using a tape measure is extremely unreliable, and use of a neonatometer, although accurate in trained hands, cannot be performed unless a baby is clinically stable. Knemometry, the measurement of knee-heel length using a purpose built measuring device, offers a means of assessing linear growth which can be used on all babies regardless of gestational age or disease severity.

The technique of knemometry was first described by Valk in $1983,{ }^{34}$ but there had been previous reports supporting the validity of measuring individual limb lengths to assess linear growth. Senecal et al measured tibial length with calipers, and compared their measurements with those obtained from serial radiographs. ${ }^{5}$ They derived centile charts for tibial length and advocated the use of this measurement in assessment of factors affecting growth in 'pathological neonates'. James et al made measurements of foot length using a purpose built measuring gauge and found such measurements to correlate closely with weight and crown-heel length, particularly in premature babies. ${ }^{6}$ The authors proposed that such measurements were of value in babies too ill for conventional measurements to be made. Brooke et al used a purpose built 'stadiometer' and calipers to measure elbow-wrist and knee-heel length and commented that such measurements are more reproducible than the normal measurements of crown-heel or crownrump length. ${ }^{78}$

Knemometry, measuring knee-heel length, has the particular advantages that the portion of the body involved is easily accessible and measurements are made across relatively fixed joints which are easy to stabilise. The knemometer first described by Valk et al is large and requires the subject to sit quietly while measurements are made. ${ }^{3}$ Under these conditions it is an extremely precise and reproducible measuring device with a technical error of measurement of $0.16 \mathrm{~mm}$ (when weekly growth rate is $0.47 \mathrm{~mm} /$ week $)^{910}$ or a coefficient of variation of $0.09 \% .{ }^{11}$ The size of this knemometer and the measurement technique are such that it is not a feasible method of measurement in children much below 3 years of age. A hand held knemometer suitable for use in babies was subsequently devised and reported by Michaelsen and colleagues in $1988^{12}$ and an evaluation published in 1991.13 For the last two years we have used measurements made with this device as part of our routine assessment of growth. In this paper we present our initial observations on the accuracy and suitability of the knemometer in neonatal practice. We have compared the knemometer with other measuring techniques and have used the measurements we have made to define normal leg length velocity centiles at different gestational ages.

\section{Methods}

(1) THE KNEMOMETER

This device (fig 1; FORCE Institutes, Copenhagen, Denmark) is a sophisticated electronic caliper that accurately measures the distance between two cups with a resolution of $0.01 \mathrm{~mm}$. One cup, in which the knee is 


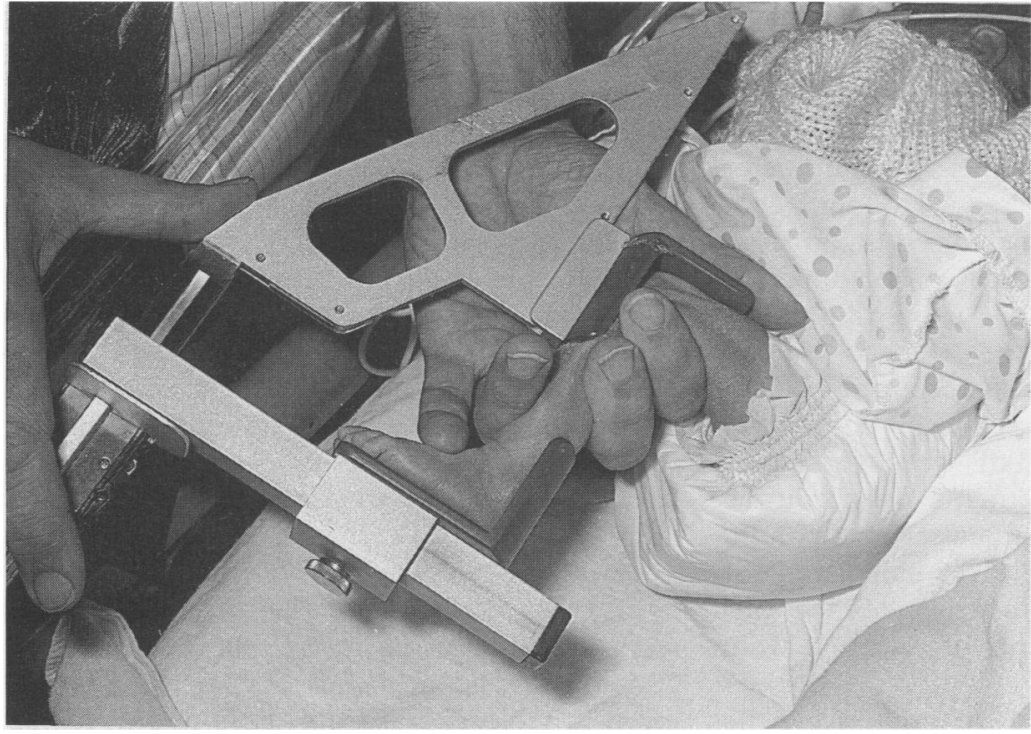

Figure 1 The knemometer. mean of the next 10 as the measurement on that occasion.

\section{(3) PRECISION}

The precision of the device was assessed using a non-deformable Perspex rod milled to exactly $100 \mathrm{~mm}$ by our medical engineering department. Thirty measurements (each being the mean of 10 readings as described above) were made, and the mean and SD of the readings calculated. Technical error of the measurement was calculated as the mean SD of all the measurements made (that is the mean of all the SDs of all the sets of 10 readings).

\section{(4) REPRODUCIBILITY}

Reproducibility was assessed in two series of 100 duplicate leg measurements. The first series was made shortly after we started to use the device and the second 10 months later. In each series, after a measurement was made, the knemometer was removed then reapplied and the measurement repeated. The difference between the two measurements was calculated and, in addition, the technical error of the measurement in each of the measurement sequences was estimated to compare the measured error for babies with that for the Perspex rod. arm. The use of this triggering system means that leg length is recorded when a standardised pressure is applied to the limb. In practice, the lower leg is exposed, the hip flexed to $90^{\circ}$ and the knee placed in the fixed cup. The foot is then placed in the second cup that is adjusted so that the knee and ankle also lie at $90^{\circ}$ and the lower leg lies parallel to the line of the knemometer. The sliding arm is then gently brought into apposition with the sole of the foot and pressure applied to the spring loaded side arm until the micrometer is triggered and the reading recorded. In this paper we will refer to a single estimate of lower leg length as a 'reading' and the mean from a series of consecutive readings as a 'measurement'.

The printer is attached to the knemometer by a $2 \mathrm{~m}$ cable and can, therefore, be positioned at a distance from the observer. In this way, all measurements were made during the validation studies with the observer blind both to the measurements being made on that occasion and to any previous measurements that had been made.

\section{(2) MEASUREMENT TECHNIQUE}

The team who developed this device recommend that five consecutive readings are made, and the mean of these five recorded as the measurement on that occasion. In their validation, the authors note a significant trend within a series of readings that they attribute to an interaction between the observer and the infant. ${ }^{13}$ We noted a similar trend and evaluated the effect of changing the number of readings made. Observations made led to an initial technique of making three readings, discarding the results, and then taking the

\section{(5) INTEROBSERVER VARIATION}

Measurements made by two observers were recorded on six occasions. One observer had gained considerable experience in the technique, while the other had little experience before starting the comparisons. Each observer made 10 consecutive readings and the mean of these was used for comparison. The difference between the two observers for each baby on each occasion was calculated and, where several measurements were available for a single baby, estimated leg length velocity was calculated for the two observers.

\section{(6) MEASUREMENTS OF LEG LENGTH}

Measurements have been made by a single experienced observer (ATG) on most babies admitted to our unit. Leg length is measured on the day of birth and at two to three day intervals thereafter. The observer is normally blind to the measurements made on that occasion and to the previous measurements made on the individual baby. Results are collated at the time of discharge, and the records examined to extract information concerning events which might influence growth. Our observations have suggested that the best estimate of average leg length velocity is obtained from a linear regression analysis of all measurements made. We have, therefore, used this method to quantify leg length velocity in individual babies. We have obtained measurements at birth on 324 babies and have combined this data to obtain an estimate of the growth of the lower leg in utero. 
(7) COMPARISON WITH OTHER MEASUREMENT TECHNIQUES

Technical error of the electronic scales (Viamed Baby scales, Viamed Ltd, Keighley, West Yorkshire) and the neonatometer (Harpenden Neonatometer, Holtain Ltd, Crymmych, Wales) routinely used on our unit was assessed. Ten consecutive readings of length or weight were made using the appropriate device. Babies were weighed by the nursing staff who made the routine weight measurements, length was measured by two middle grade medical staff who were used to making such measurements on a routine clinical basis. Measurements were made on $\mathbf{3 0}$ babies, and the technical error calculated for this series. To allow comparison of the different methods, coefficients of variation were calculated for each.

All statistical analyses were made using the Statsview package.

\section{Results}

(1) MEASUREMENT TECHNIQUE

Figure 2 shows means obtained from 30 sets of 13 sequential readings made on a single occasion on different babies. Figure $2 \mathrm{~A}$ shows the means obtained from considering the first five readings only, as recommended by Michaelsen. ${ }^{13}$ There is a strong trend within the series, and a total change of nearly $1 \mathrm{~mm}$. From careful observation of the limb being measured and from consideration of a large
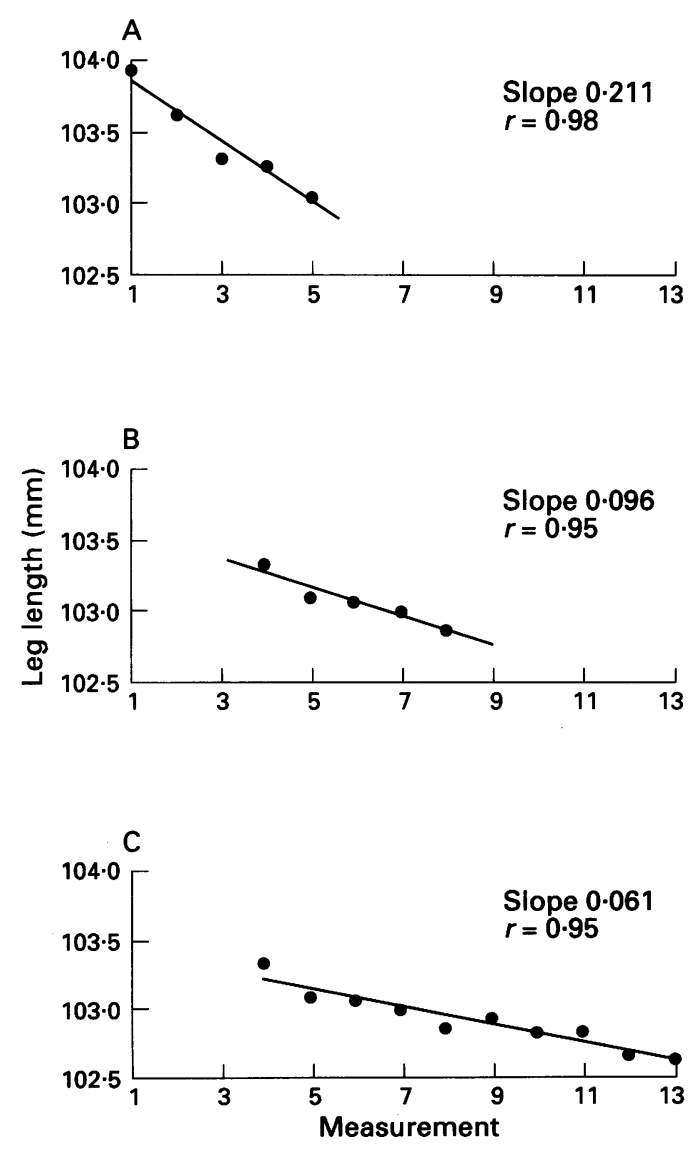

Figure 2 Measurement techniques: means from 30 sets of 13 consecutive measurements. (A) First five measurements; (B) first three measurements discarded then five; (C) first three omitted, next 10 consecutive measurements. number of measurements, it was apparent that there was significant soft tissue compression, most evident during the first three measurements. We therefore observed the effect of omitting the first three readings and recording the next five (fig 2B). The slope is less marked and the trend still present. We then examined whether this could be improved further by taking the next 10, as opposed to five, measurements (fig 2C). A significant trend remains but the slope of the line is less than with either of the other two measurement techniques. To assess the effect of the three techniques on the precision of the measurement, the mean SD for all the readings within a series was calculated. Two such evaluations have been performed. The first took place shortly after starting to use the knemometer and the second a year later. The results are given in table 1 , and from these figures it can be seen that discarding the first three measurements appeared to increase the precision, as did increasing a series from five to 10 readings when the technique was first assessed. There is, however, evidence of a learning effect, with a decrease of mean SD over a year and the benefit of 10 readings instead of five has been lost.

We have thus evolved a standard technique whereby three compressions are made, the results discarded, and the next 5 recorded. The mean of these five readings is taken as the lower leg length on that occasion.

It is usually possible to measure both legs in less than one minute, and measurements can be made without waking a sleeping baby and without causing any disturbance to a ventilated baby, as indicated by changes in pulse, blood pressure, or oxygen saturation. Handling of a baby is minimal, and measurements can be made without removing a baby from an incubator or detaching the baby from the ventilator.

\section{(2) PRECISION}

Thirty measurements made on a $100 \mathrm{~mm}$ Perspex rod gave a mean length of $99.993 \mathrm{~mm}$ and a mean SD from the 30 measurements of $0.058 \mathrm{~mm}$. The mean estimate of the length was extremely close to the known length and the technical error represented less than $0.06 \%$ of the length of the 'phantom limb'.

\section{(3) REPRODUCIBILITY}

Two series of duplicate measurements were made 10 months apart. In each series, 100 limbs were measured twice on a single occasion as detailed above. The technical error of the measurement derived from all 200

Table 1 Technical error of leg length measurements made using different series of measurements

\begin{tabular}{lll}
\hline \multirow{2}{*}{$\begin{array}{l}\text { No of measurements } \\
\text { used }\end{array}$} & \multicolumn{2}{c}{ Mean SD of the measurement series } \\
\hline fune 1991 & fuly 1992 \\
\hline $1-5$ & $0 \cdot 68$ & 0.42 \\
$4-8$ & 0.59 & 0.34 \\
$4-13$ & 0.52 & 0.35 \\
\hline
\end{tabular}


measurements was $0.50 \mathrm{~mm}$ (with a mean leg length of $105.21 \mathrm{~mm}$ ) in April 1991 and 0.31 $\mathrm{mm}$ (with a mean leg length of $98.49 \mathrm{~mm}$ ) in February 1992.

The technical error of the measurement technique is less than one day of growth of the lower leg, and alternate day measurements will, therefore, reflect true changes in leg length. There is again evidence of a learning phenomenon, with an improved SD of measurement in the second series.

Each of the individual duplicate measurements from the first series are shown in fig 3. Each point represents the difference between the two measurements expressed as a percentage of the first measurement and the points are plotted against the length of the leg being measured. The data have been expressed in

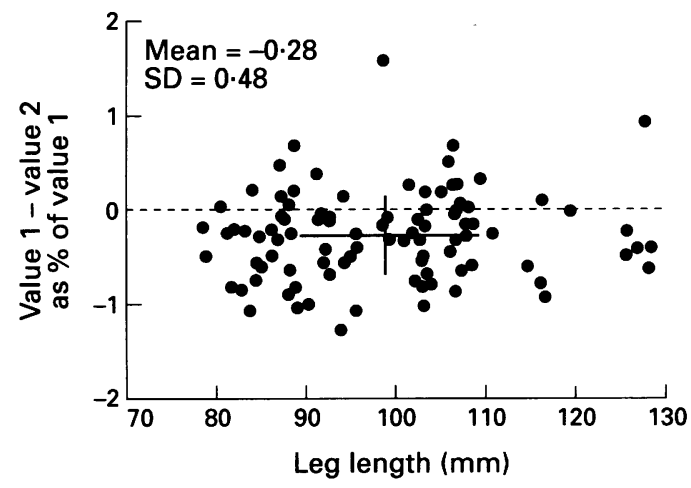

Figure 3 Reproducibility: 100 duplicate measurements made by a single observer.

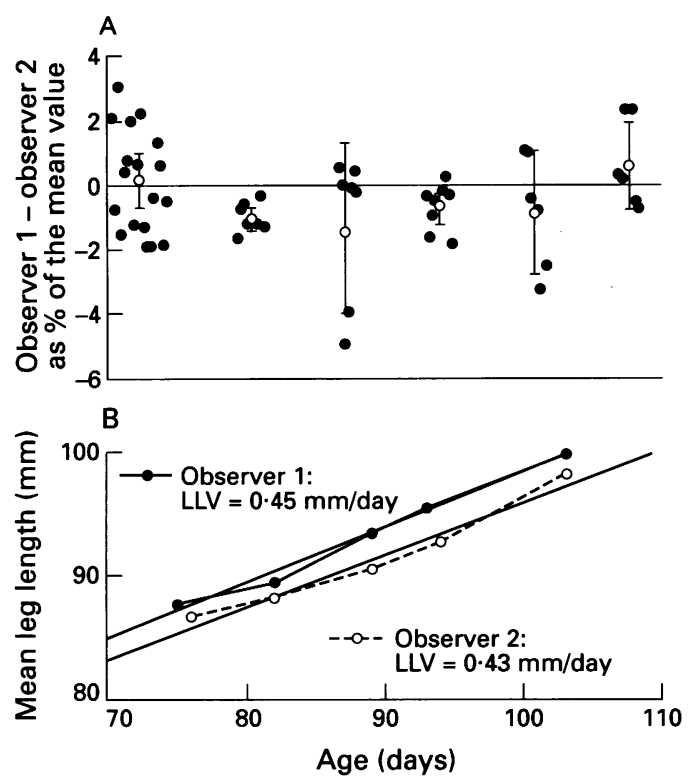

Figure 4 (A) Interobserver variation: each point represents the difference between the two observers' measurements expressed as a percentage of the mean of the two measurements. Open circles and bars are the mean (95\% CI). (B) Leg length velocity (LLV) calculated for two observers showing consistent difference between length measured but similar velocities.

Table 2 Comparison of technical error of knemometry with measurement of weight by electronic scales and length by neonatometer

\begin{tabular}{lccc}
\hline & Electronic scales & Neonatometer & Knemometer \\
\hline Mean & $2087.4 \mathrm{~g}$ & $48 \cdot 164 \mathrm{~cm}$ & $98.49 \mathrm{~mm}$ \\
Mean SD & $5 \cdot 7$ & 0.28 & 0.31 \\
Coefficient of variation (\%) & 0.27 & 0.58 & 0.31 \\
\hline
\end{tabular}

this way to see if there is any consistent trend in the differences determined either by the sequence of the measurements or the length of the limb. The mean value for the second measurement is $0.28 \mathrm{~mm}$ less than that for the first measurement with a SD of 0.48 . In 78 of the 100 measurements, the second value was less than the first, again suggesting that there may be progressive compression of the limb. There is no significant correlation between the length of the limb and the magnitude of the difference, indicating that the error is not influenced by the length of the limb being measured.

\section{(4) INTEROBSERVER VARIATION}

All measurements made for the evaluation of the device and for any assessment of longitudinal growth were performed by a single observer. To assess interobserver variation, the measurements were repeated by a second observer on a number of occasions. The results of six such occasions are shown in fig $4 \mathrm{~A}$. The difference between the two observers is expressed as a percentage of the mean of the two measurements. It can be seen from the scatter of the points that the agreement between the two observers in the estimation of absolute length was often poor, with differences ranging from $+3 \cdot 6 \%$ to $-4 \cdot 8 \%$. This reflects the way each observer orientates the limb in the neonatometer. Estimation of the change in length, however, shows more consistency. An example is shown in fig $4 \mathrm{~B}$ where five measurements were made on one baby over a 30 day period by two observers. The length measured by observer 2 is consistently less than that measured by observer 1 , but a calculation of leg length velocity by linear regression analysis of all points is almost identical, $0.43 \mathrm{~mm} /$ day against $0.45 \mathrm{~mm} /$ day.

\section{(5) COMPARISON WITH OTHER MEASURING DEVICES}

Results of 30 estimates of weight and length made using electronic scales and a neonatometer are shown in table 2 and compared with the results of the second series of measurements made with the knemometer. Each estimate, from a different individual, is the mean of 10 consecutive measurements on that individual. This is obviously an artificial comparison as under normal circumstances only single measurements of weight and length would be made. In this context, however, it has allowed a comparison of the reproducibility of the two techniques to be made.

(6) MEASUREMENTS OF LEG LENGTH AT BIRTH Lower leg length was measured in the majority of babies admitted to our neonatal unit within the first 24 hours of life. Figure 5 shows these initial measurements made in 324 babies grouped together for each week of gestational age from 23 to 42 weeks. Babies with congenital abnormalities or other conditions that might abnormally influence in utero growth 


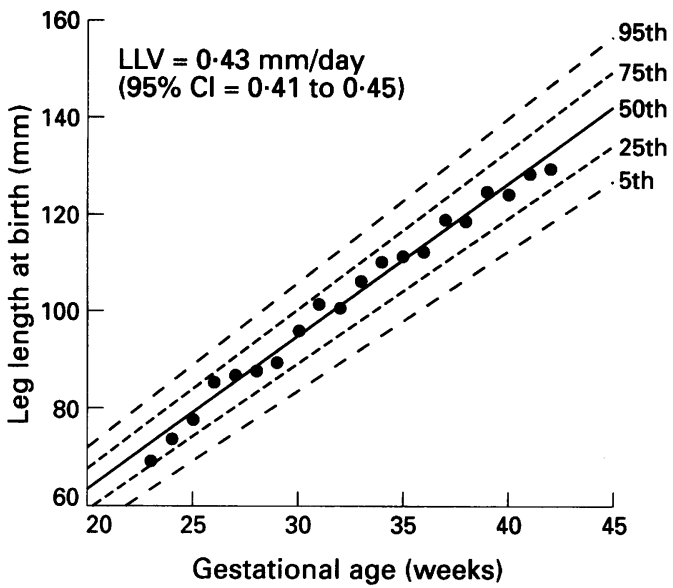

Figure 5 Mean (SD) leg length on day of birth for 324 babies grouped by week of gestation age; 5th to 95th centiles are shown. $L L V=$ leg length velocity.

Table 3 Numbers of babies of different gestational ages with leg length measured on the day of birth

\begin{tabular}{lrll}
\hline $\begin{array}{l}\text { Gestational } \\
\text { age (weeks) }\end{array}$ & No & $\begin{array}{l}\text { Mean leg } \\
\text { length }(\mathrm{mm})\end{array}$ & $S D$ \\
\hline 23 & 4 & $69 \cdot 2$ & $3 \cdot 0$ \\
24 & 5 & $73 \cdot 7$ & $2 \cdot 2$ \\
25 & 8 & $77 \cdot 7$ & $4 \cdot 8$ \\
26 & 14 & $85 \cdot 4$ & $4 \cdot 9$ \\
27 & 20 & $87 \cdot 0$ & $5 \cdot 7$ \\
28 & 10 & $88 \cdot 0$ & $6 \cdot 0$ \\
29 & 8 & $89 \cdot 6$ & $7 \cdot 3$ \\
30 & 14 & $96 \cdot 2$ & $4 \cdot 6$ \\
31 & 22 & $101 \cdot 9$ & $3 \cdot 8$ \\
32 & 37 & $100 \cdot 8$ & $7 \cdot 5$ \\
33 & 37 & $106 \cdot 3$ & $5 \cdot 6$ \\
34 & 31 & $110 \cdot 4$ & $6 \cdot 8$ \\
35 & 31 & $111 \cdot 6$ & $5 \cdot 1$ \\
36 & 16 & $112 \cdot 4$ & $9 \cdot 9$ \\
37 & 9 & $119 \cdot 2$ & $5 \cdot 1$ \\
38 & 6 & $118 \cdot 8$ & $6 \cdot 3$ \\
39 & 7 & $125 \cdot 0$ & $8 \cdot 5$ \\
40 & 31 & $124 \cdot 4$ & $8 \cdot 8$ \\
41 & 7 & $128 \cdot 3$ & $4 \cdot 8$ \\
42 & 7 & $129 \cdot 8$ & $2 \cdot 2$ \\
\hline
\end{tabular}

(for example diabetes mellitus) have been excluded from this analysis, as have any babies in whom gestational age was uncertain. Linear regression analysis of all the measurements made gives the closest approximation to the relationship between the points, and the slope of this regression line gives an estimated in utero lower leg growth rate of $0.43 \mathrm{~mm} /$ day with a $95 \%$ confidence interval (CI) of 0.41 to $0 \cdot 45$. We have used linear regression analysis of the SDs to give approximate centile lines for the leg length at different gestational ages. The details of the numbers and leg lengths at different gestational ages are given in table 3.

Because of the relatively small number of babies we have not attempted to subdivide the groups by sex. Boys are larger than girls in all growth parameters at birth and it would be expected that this would also apply to leg length. A limited analysis of this group suggests that the differences are small. At 29 weeks' gestation mean (SD) leg length was $73.6(2.5)$ $\mathrm{mm}$ for girls and $73.7(2.5) \mathrm{mm}$ for boys. At 32 weeks the values were $101.9(7 \cdot 2) \mathrm{mm}$ for girls and $103.2(8.2) \mathrm{mm}$ for boys. For the whole study boys predominate, with a male to female ratio of 3:2. The centiles may therefore represent a slight underestimate for boys and a larger overestimate for girls.

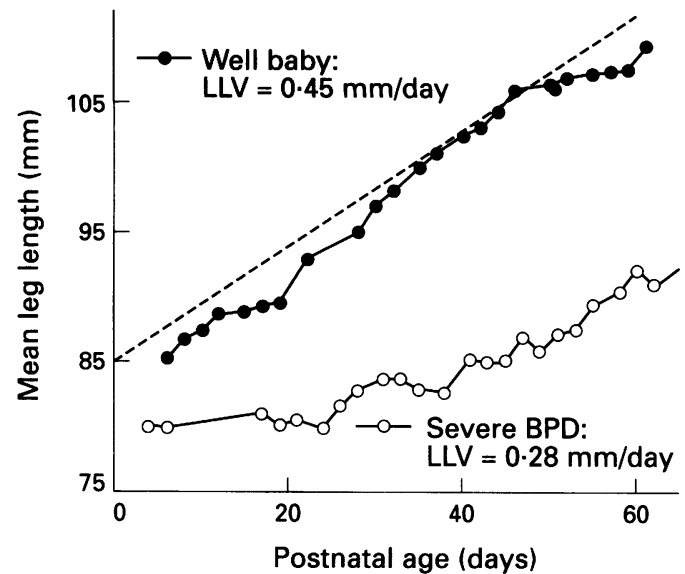

Figure 6 Linear growth patterns for a well baby compared with a baby with severe bronchopulmonary dysplasia $(B D P)$. The dotted line is the mean of the measurements made at birth and represents a predicted in utero growth rate of $0.43 \mathrm{~mm} /$ day. $L L V=$ leg length velocity.

(7) INDIVIDUAL GROWTH PATTERNS

Leg length was measured on all subjects at two to three day intervals throughout admission to our unit. To remove observer bias, measurements were made with the observer blind to previous measurements, and results compiled after the baby was discharged. Two typical growth charts are shown in fig 6 in which the superimposed line is the 50 th centile from fig 5. Both babies were born at 27 weeks' gestation. The lower leg growth represented by the solid circles was from a baby who required ventilation for less than 12 hours and oxygen for less than one day. Growth was virtually parallel to the predicted 'in utero' growth line throughout and calculated leg length velocity was $0.45 \mathrm{~mm} /$ day. The lower leg growth represented by the open circles is from a baby who required ventilation for 40 days and developed severe bronchopulmonary dysplasia necessitating home oxygen. Leg length dropped away from the ideal line from birth onwards and leg length velocity was only $0 \cdot 28$ $\mathrm{mm} /$ day.

\section{(8) DETAILED ASSESSMENT OF INDIVIDUAL} GROWTH PATTERNS

Figure 7 shows two examples of individual growth changes. Figure 7A shows leg length and weight in a well baby of 27 weeks' gestation. This baby's admission could be divided into three phases shown by the bars. In the first and third periods the baby received a standard term baby formula feed and in the intervening period received a premature baby formula feed. The volume of the premature baby feed given was less than that of the term formula feed and calculated energy intake was only

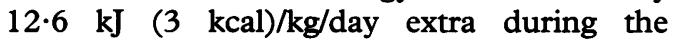
premature baby formula period. There is an immediate change in leg growth and weight gain corresponding to the introduction of the premature baby formula. Weight gain increases by more than $240 \%$ and leg length velocity by $77 \%$ and, in this example, both weight and leg measurement revert to the initial pattern of growth after the feed is changed back to standard term formula. 

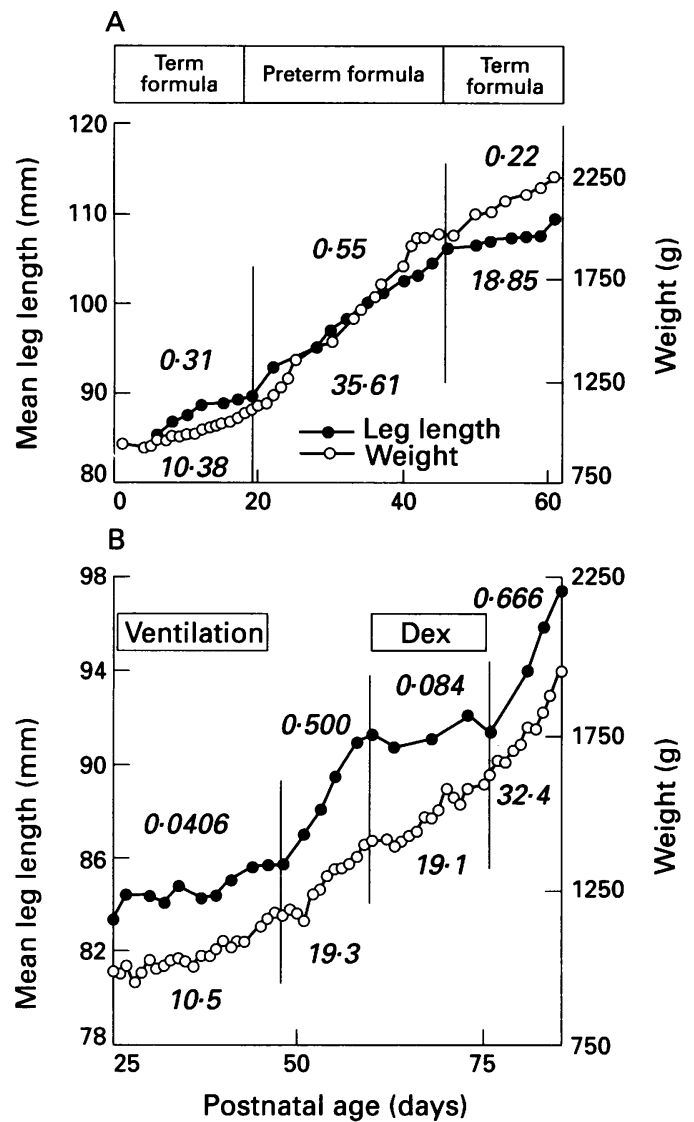

Figure 7 Individual growth patterns. (A) Changes in leg length and weight associated with changes in feed. Numbers in italics above the line are leg length velocity in $\mathrm{mm} / d a y$, those below the line are weight gain in g/day. (B) Phasic changes in leg length and weight in a baby of 28 weeks' gestation with severe bronchopulmonary dysplasia.

Numbers in italics above the line are the leg length velocity in $\mathrm{mm} /$ day, those below the line are weight gain in g/day. Dex=dexamethasone.

Figure 7B shows leg length and weight for a baby of 27 weeks' gestation who required ventilation until day 49 . Lower leg growth is very poor during this period as is weight gain. Ventilation was discontinued at day 49 , and there is an immediate and dramatic increase in leg length velocity with a much less marked effect on weight gain. During this period, however, oxygen requirements rose, and a course of dexamethasone was given between days 63 and 76. Leg length velocity decreases dramatically while weight gain does not change. When steroids are discontinued, there is an immediate rapid increase in linear growth to a rate higher than that before steroids were commenced.

\section{Discussion}

The neonatal knemometer has been designed to measure short term changes in lower leg length and can be used in even the sickest and most premature babies. There is extremely high precision when the knemometer is used to measure a non-deformable object, but technical error increases from $0.058 \mathrm{~mm}$ to 0.31 $\mathrm{mm}$ when a limb is measured. A similar observation has been made by Voss et al in evaluation of height measurement in children. ${ }^{14}$ Although the technical error is moderately high, it is less than a single day's growth in a normal baby and approximately the same as that seen in a sick infant with impaired growth. The technical error of the neonatal knemometer was $0.31 \mathrm{~mm}$ in comparison to $0.16 \mathrm{~mm}$ for the large knemometer, ${ }^{9}$ but this must be contrasted with the documented lower leg growth velocity of 0.43 $\mathrm{mm} /$ day in a baby and $0.47 \mathrm{~mm} /$ week in a child.

Soft tissue compression during initial application of the knemometer is an important source of error with this technique, and it is, therefore, advisable to develop a standardised measurement routine. This error can be reduced by omitting the first three readings during which the majority of compression occurs. In our initial evaluation, it appeared that taking the mean of the next 10 readings gave the smallest error, but in our recent repeat series this no longer appeared to be the case. We, therefore, recommend making three readings, which are then discarded, and taking the mean of the next five readings as the estimate of lower leg length.

The reduction in technical error assessed in the two large duplicate studies implies a prolonged 'learning curve'. We would recommend that sequential observations on a single baby be made by one experienced observer only. If two or more observers are involved, they should all have some experience with the technique, which should be confirmed by a validation study before studies are commenced. All our data for growth centiles was derived by a single observer. Because of the variation that we have observed between different observers these charts would require validation by others before assuming they are widely applicable. Although interobserver variation may question the validity of the absolute values for leg length centiles the estimates of velocity should not be greatly affected.

Comparison of measurements by knemometry with those by other techniques suggests that weight is the most precise measurement and length (by neonatometry) the least, as judged by the coefficient of variation. However, length measurements by neonatometer are simply not feasible on a sick ventilated baby and for these repeat measurements of weight and length only comparatively well and clinically stable babies were involved, whereas it was possible to assess all babies by knemometry. Weight measurements in such babies become less precise as attached lines, tubes and wires have to be suspended above the scales and repeat measurements expose the baby to an increased risk of accidental removal of cannulae and endotracheal tubes. Knemometry is unique in allowing repeat measurements to be made at frequent intervals from birth onwards in any baby.

One assumption that must be made in knemometry is that growth of an isolated limb is representative of growth of the whole body. It is not possible to use leg length measurements in a child to predict increment in stature, ${ }^{11} 15$ but animal and human studies, as well as our own unpublished observations, have suggested that an association may exist in 
infants. Richardson et al found long bone length to be the single most useful measurement for predicting developmental age in Jersey cows. ${ }^{16}$ Bishop et al have shown close agreement between measurements of ulnar length and overall length in term babies. ${ }^{17}$

Measurements of leg length made at birth have suggested an approximate leg length velocity between 24 and 42 weeks' gestation of $0.43 \mathrm{~mm} /$ day $(95 \%$ CI 0.41 to 0.45$)$. Over this period, the relationship between leg length and gestational age most closely approximates a straight line. The validity of such a plot to estimate ideal growth rate after birth is uncertain. The first, possibly unjustified, assumption is that all the babies in whom measurements were made were growing normally before birth. Abnormal growth could be expected to be a part of the reason for the premature delivery in some of the babies measured. It is not possible to isolate those babies in whom this might be the case, and we have, therefore, included all babies other than those with congenital abnormalities or factors which would obviously predispose to abnormal growth. The estimate of growth velocity must, therefore, be accepted as an approximation at best. The second assumption is that extrauterine and intrauterine growth proceed at the same rate. Largo et al have suggested that intrauterine growth standards cannot be applied to extrauterine growth. ${ }^{18}$ The data on which these conclusions are based appear to be due to a discrepancy in growth rates measured around term. The example shown in fig 6 suggests that any discrepancy is small. Ideally we should use data derived from longitudinal studies in individual babies but by virtue of the population under study this is simply not possible. As we have repeatedly seen how easily growth may be affected by many different factors in this vulnerable population the chance of longitudinal data from a very premature baby providing reliable information on normal growth patterns is remote. The good agreement that we have seen between our lines and the growth of well babies suggests that the charts may be used as a good approximation of the normal growth rate.

Individual growth patterns as shown here clearly display different growth rates in babies. The well baby and the baby with bronchopulmonary dysplasia, although born at the same gestation, show very different leg length velocities, providing results which are interesting and complementary to the measurements of weight and length. It would appear that knemometry may detect small changes in bone growth that are not shown by changes in weight, and conversely changes in weight may occur that are not accompanied by changes in linear growth. Logically it would seem likely that measurements of weight are more prone to distortion due to fluid shifts than are measurements of length. It is of interest to note that, as shown in fig $7 \mathrm{~A}$, changes in feed result in a substantial increase in weight gain with a less marked increase in length, while dexamethasone was associated with little change in weight and substantial change in leg length velocity.

In conclusion, we believe that knemometry is a valuable technique for use in neonatal care. It has a technical error that is substantially less than a single day's growth. Interobserver estimations of absolute length show poor agreement however, and measurements should be made by a single observer. Long term measurements complement data already obtainable by other techniques, but have the advantage that measurements can be performed more easily, quickly and with much less disturbance in any situation. In view of the very high limb growth rates that we have measured, and the rapid changes in growth that may be observed, we feel that knemometry has a unique role in the assessment of factors that influence short term growth rate in the neonate.

1 Babson SG, Bramhall JL. Diet and growth in the premature infant. F Pediatr 1969; 74: 890-900.

2 Gaull GE, Rassin DK, Raiha NCR Protein intake of premature infants: a reply. F Pediatr 1977; 90: 507-10. premature infants: a reply. $f$ Pediatr 1977; 90 : $507-10$. Kloppenborg PWC, Cassorla FG, Schutte EAST. Accurate measurements of the lower leg length and the ulnar length and its application short term growth measurement. Growth 1983; 47: 53-66.

4 Valk IM, Langhout-Chabloz AME, van Gilst W. Intradaily variation of the human lower leg length and short term growth - a longitudinal study in fourteen children. Growth 1983; 47: 397-402.

5 Senecal J, Simon J, Defawe G, Adde E. Interet et technique de la mesure de la longeur du tibia chez le nouveau-ne pathologique. Seminars Hopitals de Paris 1979; 55: 666-9. pathologique. Seminars Hopitals de Paris 1979; 55: 666-9.
6 James DK, Dryburgh EH, Chiswick ML. Foot length - a new and potentially useful measurement in the neonate. new and potentially useful measu

7 Brooke OG, Alvear J, Arnold M. Energy retention, energy expenditure, and growth in healthy immature infants. Pediatr Res 1979; 13: 215-20.

8 Brooke OG, Onubogo O, Heath R, Carter ND. Human milk and preterm formula compared for effects on growth and metabolism. Arch Dis Child 1987; 62: 917-23.

9 Hermanussen M. Knemometry, a new tool for the measurement of growth. A review, Eur f Pediatr 1988; 147: 350-5.

10 Hermanussen M, Geiger-Benoit $\mathrm{K}$, Burmeister J, Sippell WG. Knemometry in childhood: accuracy and standardisation of a new technique of lower leg length measuresation of a new technique of lower

11 Wales JKH, Milner RDG. Knemometry in the assessment of linear growth. Arch Dis Child 1987; 62: 166-71.

12 Michaelsen KF, Mortensen HB, Shakkebak NE. A new knemometer for assessing linear growth. Pediatr Res 1988; 24: 528 .

13 Michaelsen KF, Skov L, Badsberg JH, Jorgensen M. Shortterm measurement of linear growth in preterm infants: validation of a hand-held knemometer. Pediatr Res 1991; 30: 464-8.

14 Voss LD, Bailey BJR, Cumming K, Wilkin TJ, Betts PR. The reliability of height measurement (the Wessex Growth Study). Arch Dis Child 1990; 65: 1340-4.

15 Wit JM, van Kalsbeek J, van Wijk-Hoek JM, Leppink GJ Assessment of the usefulness of weekly knemometric meaAssessment of the usefulness of weekly knemometric mea76: $974-80$.

16 Richardson C, Jones PC, Barbard V, Herbert CN, Terlecki $S$, Wijeratne WVS. Estimation of the developmental age of the bovine fetus and newborn calf. Vet Rec 1990; 126: 279-84

17 Bishop NJ, King FJ, Lucas A. Linear growth in the early neonatal period. Arch Dis Child 1990; 65: 707-8.

18 Largo RH, Walli R, Duc G, Fanconi A, Prader A. Evaluation of perinatal growth. Presentation of combined intra- and extrauterine growth standards for weight, length and head circumference. Helvetica Paediatrica Acta 1980; 35: 419-36. 